\title{
LUNG FUNCTION STUDIES. V. RESPIRATORY DEAD SPACE IN OLD AGE AND IN PULMONARY EMPHYSEMA ${ }^{1}$
}

\author{
BY WARD S. FOWLER 2 \\ (From the Department of Physiology and Pharmacology, Graduate School of Medicine, Uni- \\ versity of Pennsylvania, Philadelphia)
}

(Received for publication May 24, 1950; accepted, July 24, 1950)

At the end of inspiration, the respiratory dead space contains gas which merely fills the conducting airway and does not contribute to dilution of alveolar gas. Precise knowledge of the volume of this gas is important to methods of estimating the uniformity of alveolar ventilation (1-3) and to the evaluation of alveolar ventilation-perfusion relationships in normal subjects and in patients with pulmonary disease (4). The volume of the respiratory dead space can be measured directly and accurately in subjects with normal intrapulmonary gas mixing (5), but the possibility of similar measurements in patients with pulmonary emphysema has been doubted $(2,6)$.

The development by Lilly and Hervey of the $\mathrm{N}_{2}$ meter, which permits a continuous and hence complete analysis of the $\mathrm{N}_{2}$ concentration of respired gases, has made possible the studies reported here. These studies indicate that the respiratory dead space can be measured in subjects with pulmonary disease such as pulmonary emphysema. Since many patients with emphysema are elderly, respiratory dead space was measured in a group of men of similar age, but without cardiopulmonary disease, to serve as a basis for comparison. This also afforded an opportunity to see whether respiratory dead space changed consistently with advancing age.

\section{METHODS}

\section{General}

Much of the controversy about the volume of the respiratory dead space, both in normal and diseased subjects, has arisen from technical and conceptual inadequacies. For this reason, our method and the tests required to validate it are presented in detail in this section.

Instrumental and other details have been described previously (5). In brief the method consists of con-

1 This research was supported in part by a grant from the Commonwealth Fund and in part by a research grant from the National Heart Institute, United States Public Health Service.

2 National Institute of Health Postdoctorate Fellow. tinuous analysis and photographic recording of (1) expiratory volume flow and (2) $\mathrm{N}_{2}$ concentration or respired gases passing through the mouth piece during and after the change from breathing room air to breathing $99.6 \% \mathrm{O}_{2}$. The subject, after semi-reclining in bed (head and trunk elevated $50-60^{\circ}$ ) for at least ten minutes, breathes room air through a mouth-piece attached to a four-way valve. At the end of a normal expiration the valve is turned so that the room air orifice is closed, and $\mathrm{O}_{2}$, delivered through a demand valve, is now inspired; expired gas passes through a flow meter, 30 inches of flexible rubber tubing ( $2 \mathrm{~cm}$ I.D.), and the expiratory valve, to a counter-balanced 120 liter recording spirometer. The flow meter is calibrated by relating the actual volume (measured spirometrically) to the area bounded by the flow record and its zero line. Details of the expiratory flow pattern cannot be recorded faithfully by this technique, but it is satisfactory for the volume measurements required for estimation of dead space. Respiratory frequency, tidal and minute volume are also measured with the same apparatus; either compressed air or $\mathrm{O}_{2}$ is delivered by a demand regulator.

\section{Description and interpretation of records}

With this procedure, the time, $\mathrm{N}_{2}$ concentration and volume flow of each expiration are recorded continuously. Figure 1(A) shows a typical normal record of a single expiration, which has been replotted as $\mathrm{N}_{2}$ concentration against the volume expired. It can be divided into three successive phases in which $\mathrm{N}_{2}$ concentration (1) equals inspired concentration $(0.4 \%)$, (2) changes in an Sshaped fashion, and (3) is practically rectilinear (7). Phases 1 and 2 represent washing out of the dead space and phase 3 represents alveolar gas. These three phases are also present in other expirations, although the alveolar $\mathrm{N}_{2}$ concentration is progressively reduced with successive inspirations of $\mathrm{O}_{2}$. For measurement of respiratory dead space by Bohr's formula, it is necessary that the dead space be completely washed out, and the $\mathrm{N}_{2}$ concentration of the expired alveolar gas be known. In normal subjects, the completion of wash-out is indicated by the end of the sigmoid second phase; the gas expired during phase 3 satisfies a ventilatory criterion for alveolar gas and usually has a nearly uniform $\mathrm{N}_{2}$ concentration (8). Thus completion of phase 2 can be identified directly on the photographic record by drawing a straight line along the top of phase 3 , or "plateau," extending it to the left and noting the point at which this line becomes tangent to the rising sigmoid curve. 


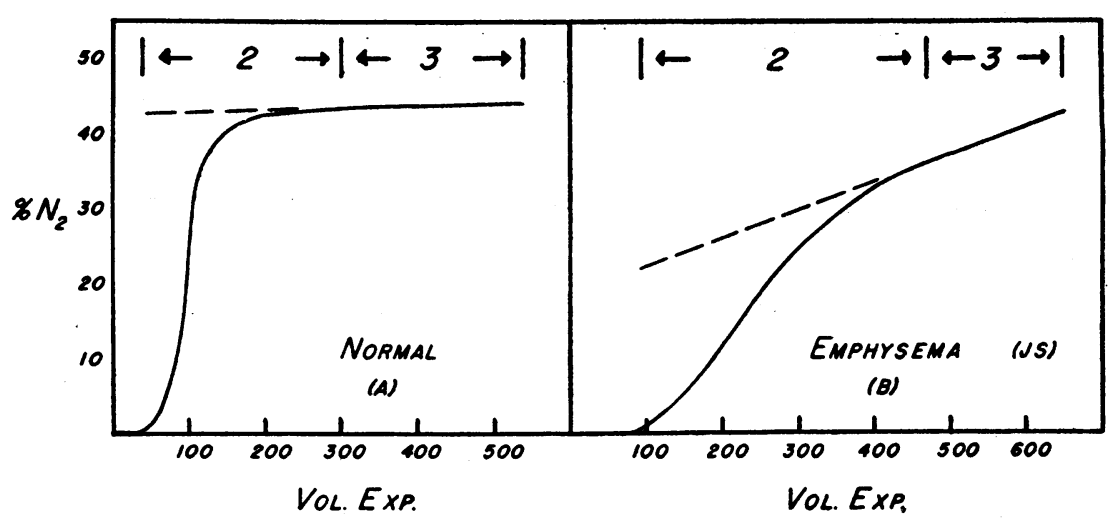

Fig. 1. Records of $\mathrm{N}_{2}$ Concentration and Volume of Single Quiet Expirations after $\mathrm{O}_{2}$ Inhalation, Illustrating Three Phases, and Steep Slope of Phase 3 in Record (B) of Subject J. S. with Pulmonary Emphysema

This cannot be done for many patients with pulmonary disease and some healthy elderly persons. The linearity of phase 3 becomes apparent only when $\mathrm{N}_{2}$ concentration is plotted against expired volume, as illustrated by Figure 1(B). The criterion used previously to interpret the phases in young normal adults is not applicable here, because pulmonary ventilation deviates too greatly from uniformity. However, two other approaches have been useful in confirming the presence and interpretation of the phases in records of patients wtih pulmonary disease.

(A) In a separate procedure, the subject, previously breathing room air, expires maximally; then without pause, he inspires $\mathrm{O}_{2}$ maximally and then makes another maximal expiration through the flow meter to the recording spirometer. This maneuver, illustrated in Figure $2(\mathrm{~A})$, enlarges phase 3 , provides additional points

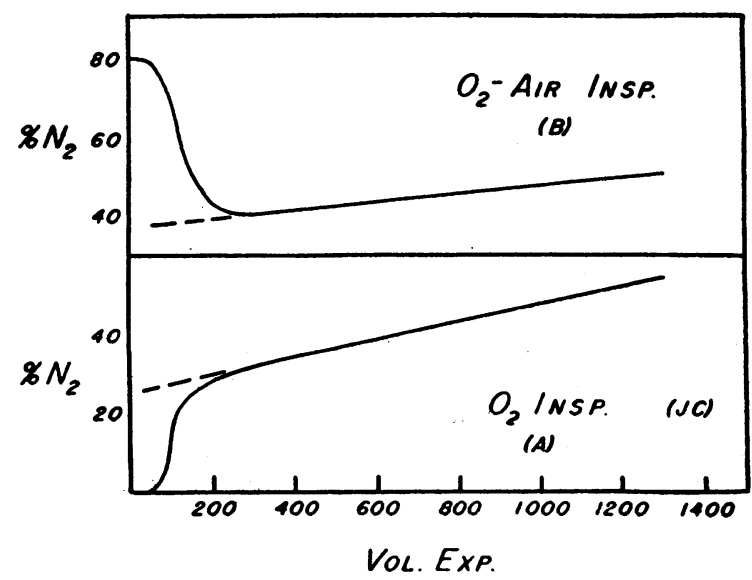

Fig. 2. Records of $\mathrm{N}_{2}$ Concentration and Volume of Single Maximal Expirations after (A) MaxiMal INSPIRATION OF $\mathrm{O}_{2}$ AND (B) Maximal Inspiration of $\mathrm{O}_{2}$-AIr Sequence by Subject J. C. with Pulmonary EMPHYSEMA

(See text.) which confirm the linearity, and also permits measurement of dead space at maximal lung inflation.

(B) In the above maneuver, the dead space is filled with $\mathrm{O}_{2}$ at the end of inspiration, and the directions of the slopes of phases 2 and 3 are similar. If the direction of slopes could be made dissimilar, this would facilitate detection of the completion of phase 2 , and also support the interpretation that this indicates the end of the dead space wash-out. This was found to be possible, particularly in abnormal subjects, by having the subject inspire $\mathrm{O}_{2}(650 \mathrm{ml})$ followed without interruption by air, and then expire maximally. This sequence was achieved by inserting an $\mathrm{O}_{2}$-filled tube between the four-way valve and the demand regulator delivering compressed air. The maximal inspired volume provides sufficient $\mathrm{O}_{2}$ to dilute alveolar $\mathrm{N}_{2}$ and also sufficient air to wash through and fill the dead space. The record of the succeeding expiration is illustrated by Figure 2(B). The direction of the slope of phase 2 is now different from that of phase 3 and the point of intersection, or completion of phase 2 , is clearly evident.

These two procedures $\left(\mathrm{O}_{2}\right.$ and $\mathrm{O}_{2}$-air inhalations $)$ were done by nine patients (five female, four male). Each showed excessive variation (steep slope) of the $\mathrm{N}_{2}$ concentration of phase 3 after $\mathrm{O}_{2}$ inhalation (of the type illustrated by Figure $2[\mathrm{~A}])$. The records were essentially similar although the patients had a variety of diseases (two emphysema, two asthma, two sarcoidosis, one each bronchiectasis, silicosis and pulmonary cancer). Four patients produced records quite like Figure $2(\mathrm{~A})$ and (B). Five patients had less steep slopes (phase 3) after inhalation of $\mathrm{O}_{2}$; these showed practically horizontal slopes after inhalation of $\mathrm{O}_{2}$ followed by air. Not only was the three-phase pattern of the curves maintained for both procedures, but also the volume characteristics. The average volume (BTPS) expired prior to completion of phase 2 was $462 \mathrm{ml}$, S.D., \pm 97 after maximal inhalations of $\mathrm{O}_{2}$, and $502 \mathrm{ml}, \mathrm{S} . \mathrm{D} . \pm 149$ after $\mathrm{O}_{2}$-air inhalations. The mean difference, $40 \mathrm{ml}$, did not vary significantly from zero. The only apparent explanation for the 
constancy of this point is that it represents completion of dead space wash-out. Armitage and Arnott suggest that the increasing $\mathrm{N}_{2}$ content later in phase 3 , as in Figure 2(A), represents a decreasing amount of admixture with $\mathrm{O}_{2}$ from the dead space, "pure" alveolar gas being expelled only at the extreme end of expiration (9). This explanation is incompatible with records like Figure $2(B)$, in which phase 3 slopes upward even though the dead space was previously filled with air. The difference in the magnitude of the slope of phase 3 with the two procedures has been discussed previously (8).

These results indicate that the records of both patients and normal subjects can be described and interpreted similarly. The hyperventilation maneuvers $A$ and $B$ add certainty to the interpretation of records of quiet expiration like Figure 1(B); on the basis of the latter records alone, one might question the existence of a distinct linear third phase. However, the volume characteristics of the hyperventilation records are larger in general than those of quiet breathing, because with maximal lung inflation the dead space and the volume needed to wash it out on expiration are enlarged. (The latter volume in our experience has not exceeded $750 \mathrm{ml}$.) In certain patients, as noted below, the dead space cannot be measured during quiet breathing, because the tidal expired volume is insufficient to establish the presence of phase 3. This difficulty can be removed by augmenting the expired volume, as by hyperventilation; however, this value for dead space may not equal that which obtains during quiet breathing, because of changes in lung inflation and inspiratory time.

\section{Dead space measurement}

The measurement of dead space by Bohr's formula, as described previously (5), requires knowledge of the $\mathrm{N}_{2}$ concentration of the alveolar gas component in the total expired volume. During expiration, some alveolar gas mixes with and washes out the inspired gas from the upper airway (phase 2). The $\mathrm{N}_{2}$ concentration of this alveolar gas is not known, but in the case of normal subjects it may be assumed that the wash-out was effected by alveolar gas having a $\mathrm{N}_{2}$ concentration practically equal to that appearing immediately after wash-out is complete. In patients with uneven pulmonary ventilation one can reasonably assume that alveolar gas composition changes during the wash-out of dead space similarly to the change observed after wash-out; this assumption is illustrated by the broken lines in Figures 1 and 2, and was made in obtaining the data in Table I.

\section{Dead space/tidal volume fraction}

Because the method used here involves the breathing of $\mathrm{O}_{2}$ which may alter the tidal volume, we measured the tidal volumes during breathing of both compressed air and $\mathrm{O}_{2}$, each averaged for periods of five minutes. For 12 healthy control subjects (three young and nine elderly men) the mean difference was not significant, amounting to an increase of $2 \%$ of tidal volume while breathing $\mathrm{O}_{2}$. However nine of 11 subjects with marked pulmonary emphysema had smaller tidal volumes when breathing $\mathrm{O}_{2}$ than when breathing air. For the patients having measurements listed in Table $\mathrm{I}$, a significant mean reduction, $17.6 \%$, was observed. This was probably related to a reduction of reflex respiratory stimulation caused by anoxemia; their average resting arterial $\mathrm{O}_{2}$ saturation was $90.6 \%$.

\section{RESULTS}

\section{Respiratory dead space in young and old men}

Measurements on 21 male subjects without clinical or fluoroscopic evidence of cardio-respiratory disease are given in Table I. The younger group consisted of six physicians and four hospital patients, the older group of 11 hospital patients.

TABLE I

Physical and respiratory data for young and old men, and male patients with pulmonary emphysema* $\dagger$

\begin{tabular}{|c|c|c|c|c|c|c|c|c|c|c|}
\hline Group & No. & & Age & Ht. & Wt. & $\begin{array}{l}\text { Tidal } \\
\text { vol. }\end{array}$ & $\begin{array}{l}\text { Resp. } \\
\text { dead } \\
\text { space }\end{array}$ & $\frac{\mathrm{RDS}}{\mathrm{TV}} \times 100$ & Resp./min. & $\begin{array}{l}\text { Resp. dead } \\
\text { space } \\
\text { max. insp. }\end{array}$ \\
\hline $\begin{array}{c}\text { Young } \\
\text { men }\end{array}$ & 10 & $\begin{array}{l}\text { Mean } \\
\text { S.D. ( } \pm) \\
\text { Range }\end{array}$ & $\begin{array}{c}y r s . \\
28.2 \\
5.5 \\
17-36\end{array}$ & $\begin{array}{c}\mathrm{cm} . \\
175.2 \\
3.9 \\
170-181\end{array}$ & $\begin{array}{c}k g . \\
71.9 \\
8.8 \\
56-84\end{array}$ & $\begin{array}{c}\text { ml. } \\
567 \\
93 \\
447-780\end{array}$ & $\begin{array}{c}\text { ml. } \\
127 \\
26 \\
102-188\end{array}$ & $\begin{array}{c}\% \\
22.6 \\
4.1 \\
16.9-30.8\end{array}$ & $\begin{array}{r}17.0 \\
6.4 \\
8-27\end{array}$ & $\begin{array}{c}\text { ml. } \\
222 \\
45 \\
155-300\end{array}$ \\
\hline $\begin{array}{l}\text { Old } \\
\text { men }\end{array}$ & 11 & $\begin{array}{l}\text { Mean } \\
\text { S.D. ( } \pm) \\
\text { Range }\end{array}$ & $\begin{array}{c}59.6 \ddagger \\
6.3 \\
53-71\end{array}$ & $\begin{array}{c}165.8 \ddagger \\
7.9 \\
153-177\end{array}$ & $\begin{array}{c}69.7 \\
12.9 \\
52-91\end{array}$ & $\begin{array}{c}623 \\
149 \\
440-880\end{array}$ & $\begin{array}{c}150 \\
31 \\
104-201\end{array}$ & $\begin{array}{c}24.9 \\
6.1 \\
14.7-34.0\end{array}$ & $\begin{array}{c}18.9 \\
3.9 \\
16-27\end{array}$ & $\begin{array}{c}220 \\
70 \\
95-318\end{array}$ \\
\hline Emphysema & 9 & $\begin{array}{l}\text { Mean } \\
\text { S.D. ( } \pm) \\
\text { Range }\end{array}$ & $\begin{array}{c}66.0+8 \\
7.4 \\
51-77\end{array}$ & $\begin{array}{c}169.9 \\
7.0 \\
158-180\end{array}$ & $\begin{array}{c}64.2 \ddagger \\
6.2 \\
55-73\end{array}$ & $\begin{array}{c}709 \\
250 \\
430-1,230\end{array}$ & $\begin{array}{c}169 \ddagger \\
34 \\
115-210\end{array}$ & $\begin{array}{c}24.7 \\
6.8 \\
16.4-37.6\end{array}$ & $\begin{array}{r}17.8 \\
6.1 \\
8-27\end{array}$ & $\begin{array}{c}232 \\
57 \\
150-295\end{array}$ \\
\hline
\end{tabular}

* All volumes expressed BTPS.

† Tidal volume, DS/TV ratio and resp./min., for young and old men pertain to breathing of $\mathrm{O}_{2}$, and for emphysema (eight cases) to breathing of air. See text.

$\ddagger$ Mean value differs significantly by small sample method from mean value for young men.

Mean value differs significantly by small sample method from mean value for old men. 
Although the mean values for dead space during quiet breathing were, respectively, 150 and $127 \mathrm{ml}$ for old and young men, the difference was not statistically significant ( $p$ between 0.1 and 0.05 ). Similar (larger) values were obtained in both age groups after the lungs had been maximally inflated. The tidal volume measurements, and dead space/tidal volume fractions pertain to breathing of $\mathrm{O}_{2}$; as noted above, no significant difference was found in 12 of these subjects between the tidal volumes during breathing of $\mathrm{O}_{2}$ or compressed air.

\section{Respiratory dead space in patients with pulmonary emphysema}

Twelve male subjects having the diagnosis of chronic pulmonary emphysema were studied; the diagnoses were based on their history and upon physical, radiological and physiological examinations. In all, $\mathrm{N}_{2}$, flow, and tidal volume measurements were made during quiet breathing of $\mathrm{O}_{2}$, and after a single maximal inspiration of $\mathrm{O}_{2}$. In 11 , as noted above, tidal volume was measured both during inhalation of $\mathrm{O}_{2}$ and of compressed air.

In three patients dead space could be measured only after maximal breathing, because their tidal volumes during quiet breathing of $\mathrm{O}_{2}(339 \mathrm{ml}$ average) presumably did not completely wash out the dead space on expiration, i.e., had no linear third phase. However, it is likely that wash-out was more nearly complete with the larger tidal volumes (410 $\mathrm{ml}$ average) associated with breathing of air. The dead space values in these patients at maximal inspiration were similar to those listed in Table I.

In the other nine, respiratory dead space could be measured during both quiet and maximal breathing. Data are given in Table I. For quiet breathing, an average dead space value for each subject was obtained by measurement of two or three representative expirations, plotted as $\mathrm{N}_{2}$ : volume curves. The mean value of $169 \mathrm{ml}$ (Table I) was significantly greater $(p<0.01)$ than the mean value, $127 \mathrm{ml}$, for the young men, but not significantly greater $(p=0.2)$ than the $150 \mathrm{ml}$ mean for the older men. The dead space values at maximal inspiration were similar in all groups.

The mean dead space/tidal volume fraction was normal, $24.7 \%$, using the tidal volume while breathing air (Table I), but significantly en- larged, $31.3 \%$, if the smaller tidal volumes due to breathing $\mathrm{O}_{2}$ were used. The conclusion that the dead space/tidal volume fraction during breathing of air by patients with emphysema is not greater than normal must be tempered by the fact that three of the 12 subjects did not completely wash out the dead space on quiet expiration and therefore it could not be measured. However if a dead space of $169 \mathrm{ml}$ is assumed for these subjects, the mean fraction for the 12 patients would be $29.5 \%$ S. D. $\pm 10.8 \%$, which is not significantly greater than the normal values $(p=.1)$.

\section{DISCUSSION}

Various observers, using different methods of measurement, have considered an actual increase of respiratory dead space in pulmonary emphysema to be unlikely $(10,11)$ or "simulated" (12) or "extremely likely" (2). The significance of measurements of respiratory dead space varies with the method used. The volume of the dead space as measured here probably approximates that of the so-called anatomical dead space. The mean values increase progressively from young to old men to patients with emphysema. However, only the mean values for young men and patients differ significantly. The small increase probably reflects the overall state of pulmonary hyperinflation exhibited by such patients during natural breathing. This might suggest that at least some parts of the bronchial tree suffer a loss of elasticity similar to that of the lung as a whole. It is speculative whether the enlargement could result from a smaller extent of gaseous diffusion between terminal bronchioles and alveolar spaces, caused by the altered peripheral architecture of the airway (13). However, at a similar degree of total pulmonary inflation, i.e., maximal inspiration, the dead space values for patients and both groups of normal subjects were similar.

A group of elderly male patients with emphysema were reported by Birath (2) to have a mean "dead space" volume of $330 \mathrm{ml}$, and a mean dead space/tidal volume fraction of $55.9 \%$. Both values are significantly greater than those in Table I. The difference is very probably due to the presence in his patients of uneven pulmonary ventilation, which with his method can make the calculated value greater than the actual volume of the respiratory dead space; a reduction in tidal 
volume of his subjects associated with rebreathing an $\mathrm{O}_{2}$-enriched gas mixture may also have contributed to the large dead space/tidal volume fraction.

When breathing air, the expired gas of emphysematous patients generally has abnormally high $\mathrm{O}_{2}$ and low $\mathrm{CO}_{2}$ concentrations (12). This finding, and various indices calculated therefrom, such as the ventilation equivalent and the "dead space"/tidal volume fraction of Riley and Cournand (4), could result from several situations. The alveolar gas component of the total expired gas could be abnormal in composition with a normal dead space/tidal volume fraction, or it could be normal in composition with an abnormally large dead space/tidal volume fraction. The physiological implications of these two situations are quite different. The data presented here indicate that, in general, the latter explanation is not tenable. However, in individual cases, particularly those with a small tidal volume, the actual dead space/ tidal volume fraction may be greater than normal, especially during the inhalation of $\mathrm{O}_{2}$.

Measurements of dead space in pulmonary emphysema were made because such patients have presented the most difficulty with older methods. These studies, while clarifying certain points, indicate one principal remaining difficulty. The presence of a linear third phase must be established to indicate complete expiratory wash-out of the dead space. In records such as Figure 1(B), phase 3 must comprise $100-200 \mathrm{ml}$ to reasonably establish the linearity. During inhalation of $\mathrm{O}_{2}$, the tidal volume of certain anoxemic patients is insufficient for this. Although dead space measurement in such patients is made possible by increasing the expired volume, this requires alteration of the natural breathing pattern, and the resulting value may not equal that which obtains during quiet breathing. Sufficient numbers and degrees of various pulmonary disease conditions have not as yet been studied to establish the universality of the three-phase pattern noted above, on which the measurement of dead space is based. In particular, the linearity of phase 3 is empirical, and depends on the sequential emptying of the lungs, as discussed previously (8). However, this pattern is clearly present in normal humans from infancy through old age, and no gross deviation has been observed in the records of more than
100 patients with various types of cardio-respiratory disease.

\section{SUMMARY}

Continuous measurement was made of $\mathrm{N}_{2}$ concentration and volume-flow of gas expired after $\mathrm{O}_{2}$ inhalation. The graph of $\mathrm{N}_{2}$ concentration plotted against volume expired during one expiration can be separated into three phases in which $\mathrm{N}_{2}$ concentration successively (1) equals inspired concentration (2) increases in an S-shaped fashion, (3) is rectilinear. Evidence has been presented previously that in normal subjects, the completion of phase 2 indicates that the dead space has been washed out and phase 3 consists of alveolar gas. In certain records obtained during quiet breathing by patients with pulmonary disease, there was uncertainty whether phase 2 was completed. For measurement of respiratory dead space it is necessary that the dead space be washed out completely and an alveolar. concentration be obtained.

The completion of phase 2 and presence of phase 3 were verified in studies on patients using maximal expirations following inspirations of $\mathrm{O}_{2}$ alone, and a sequence of $\mathrm{O}_{2}$ and air. These studies support the belief that completion of phase 2 indicates that the dead space has been washed out, and that phase 3 consists of alveolar gas; this permits the selection of a value for alveolar $\mathrm{N}_{2}$ concentration which can be used in measurement of the respiratory dead space.

Ten normal young men, 11 normal old men and 12 elderly male patients with marked pulmonary emphysema were studied in a semi-reclining position. Measurements were made of (a) respiratory dead space during quiet breathing and after maximal inspiration of $\mathrm{O}_{2}$ and (b) tidal volume during breathing of $\mathrm{O}_{2}$ and compressed air. Three patients, during inhalation of $\mathrm{O}_{2}$, did not completely wash out the dead space on expiration. The mean respiratory dead space of nine patients with emphysema, measured during quiet breathing, was $169 \mathrm{ml}$; this was significantly greater than the mean value of $127 \mathrm{ml}$ for the young men. The mean value for old men was $150 \mathrm{ml}$. The respiratory dead space after maximal inspiration was similar in all three groups. The tidal volume of patients with emphysema and anoxemia was smaller when breathing $\mathrm{O}_{2}$ than when breath- 
ing air. The significance of data dependent on the dead space/tidal volume fraction of patients with emphysema is discussed.

The author wishes to thank Dr. J. H. Comroe, Jr. for valuable advice.

\section{BIBLIOGRAPHY}

1. Bateman, J. B., The measurement of intrapulmonary mixing and pulmonary midcapacity ("functional residual air"). Proc. Staff Meet., Mayo Clin., 1946, 21, 112.

2. Birath, G., Lung volume and ventilation efficiency; changes in collapse-treated and non-collapse-treated pulmonary tuberculosis and in pulmonectomy and lobectomy. Acta med. Scandinav., 1944, Supp. 154.

3. Darling, R. C., Cournand, A., and Richards, D. W., Jr., Studies on intrapulmonary mixture of gases. V. Forms of inadequate ventilation in normal and emphysematous lungs, analyzed by means of breathing pure oxygen. J. Clin. Invest., 1944, 23, 55.

4. Riley, R. L., and Cournand, A., "Ideal" alveolar air and the analysis of ventilation-perfusion relationships in the lungs. J. Applied Physiol., 1949, 1, 825.

5. Fowler, W. S., Lung function studies. II. The re- spiratory dead space. Am. J. Physiol., 1948, 154, 405.

6. Roelsen, E., and Bay, N., Investigations of the lung function in silicotics; capacity of lungs and conditions of alveolar ventilation. Acta med. Scandinav., 1940, 103, 55.

7. Lilly, J. C., Studies on the mixing of gases within the respiratory system with a new type nitrogen meter. Federation Proc., 1946, 5, 64.

8. Fowler, W. S., Lung function studies. III. Uneven pulmonary ventilation in normal subjects and in patients with pulmonary disease. J. Applied Physiol., 1949, 2, 283.

9. Armitage, G. H., and Arnott, W. M., Air distribution in lungs during hyperventilation. J. Physiol., 1949, $109,70$.

10. Hoover, C. F., and Taylor, L., The ventilatory function of the lung in emphysema and asthma. Arch. Int. Med., 1915, 15, 1.

11. Hurtado, A., Kaltreider, N. L., Fray, W. W., Brooks, W. D. W., and McCann, W. S., Studies of total pulmonary capacity and its subdivisions. VI. Observations on cases of obstructive pulmonary emphysema. J. Clin. Invest., 1934, 13, 1027.

12. Taquini, A. C., Fasciolo, J. C., Suarez, J. R. E., and Chiodi, H., Respiration and circulation in pulmonary anoxemia. Arch. Int. Med., 1948, 82, 534.

13. Kountz, W. B., and Alexander, H. L., Emphysema. Medicine, 1934, 13, 251. 